\title{
A Study on the Biological activity of Hepatitis C Analogs Prediction by QSAR -An Insilco Approach
}

\author{
M. Padmavathi \\ Department of Biotechnology \\ DVR Dr. HS MIC College of Technology, Kanchikacherla, A.P. IINDIA
}

\begin{abstract}
The proper care for hepatitis $C$ virus (HCV) infection - with ribavirin elicits sustained responses in the patients treated. No alternatives exist for patients who are suffering with the Hepatitis $C$. The toxic side - effect of ribavirin, hemolytic anemia which often helps to a reduction of dosage and comprises treatment response. It requires a balance between the antiviral and hemolytic activities of ribavirin. By rational based drug designing approach, new analogs are designed by replacing pharmacophore groups in ligand. The modified ligand molecules are mutagenic or non-mutagenic and its fitness can detect with the ADMET and GOLD. The present paper provides the knowledge of the analog characteristics like physical, chemical and biological properties i.e., polarizability, solubility, $\log P$, refractivity, surface area and hydration energy, the optimized analogs and protein binding free energy was calculated by other Insilco tools and found the best molecule which can treat the Hepatitis $C$.
\end{abstract}

\section{Keywords: HCV, Ribavirin, ADMET, Docking, in silico tools}

\section{INTRODUCTION}

Hepatitis $-\mathrm{C}$ is a infectious disease that is caused by the Hep-C virus (HCV) ${ }^{1}$. It primarily affects liver. The virus enters the liver cells, uses the cells inner genetic machinery to make copies of it, which then infect more cells. Hep-C is an acute, it is cleared spontaneously by the body and there are no long term consequences. Hepatitis $\mathrm{C}$ is the leading cause of liver transplantation, though the virus usually recurs after transplantation ${ }^{2}$. No vaccine against hepatitis $\mathrm{C}$ is available. This liver damage can lead to cirrhosis of the liver, end stage live disease and liver cancer. People with Hep-C infection usually do not have characteristic disease symptoms. Unlike other forms of viral Hepatitis, Hep-C infection usually does not result in jaundice. When symptoms do appear, they may be vague and include tiredness, stomach pain, and rashes.

Hepatitis C infection causes acute symptoms in $15 \%$ of cases $^{3}$. Symptoms are generally mild and vague, including a decreased appetite, fatigue, nausea, muscle or joint pains, and weight loss and rarely does acute liver failure result ${ }^{4}$. Most cases of acute infection are not associated with jaundice. The infection resolves spontaneously in $10-50 \%$ of cases, which occurs more frequently in individuals who are young and female 5 .

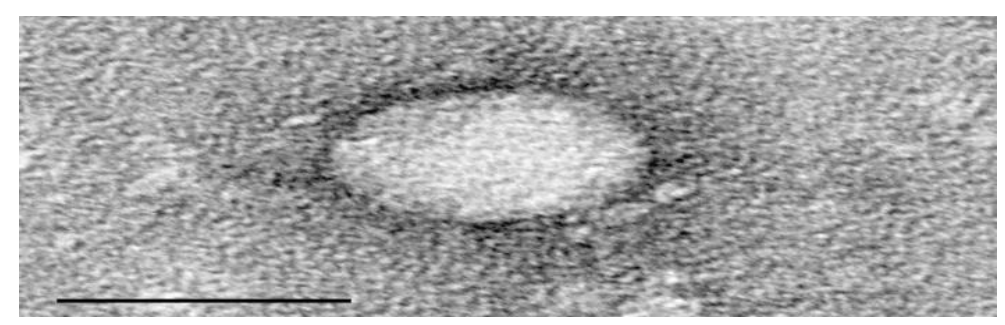

Fig 1: Hepatitis $C$ virus from the cell culture

About $80 \%$ of those exposed to the virus develop a chronic infection ${ }^{6}$. Most experience minimal or no symptoms during the initial few decades of the infection ${ }^{7}$, although chronic hepatitis $\mathrm{C}$ can be associated with fatigue ${ }^{8}$. Hepatitis $\mathrm{C}$ after many years becomes the primary cause of cirrhosis and liver cancer. About 10-30\% of people develop cirrhosis over 30 years. Cirrhosis is more common in those co-infected with hepatitis B or HIV, alcoholics, and those of male gender. Those who develop cirrhosis have a 20 -fold greater risk of hepatocellular carcinoma, a rate of $1-3 \%$ per year, and if this is complicated by excess alcohol the risk becomes 100 fold greater ${ }^{9}$. Hepatitis $\mathrm{C}$ is the cause of $27 \%$ of cirrhosis cases and $25 \%$ of hepatocellular carcinoma worldwide ${ }^{10}$.Liver cirrhosis may lead to portal hypertension, ascites (accumulation of fluid in the abdomen), easy bruising or bleeding, varices (enlarged veins, especially in the stomach and esophagus), jaundice, and a syndrome of cognitive impairment known as hepatic encephalopathy. It is a common cause for requiring a liver transplant ${ }^{11}$. 
Hepatitis C is also rarely associated with Sjögren's syndrome (an autoimmune disorder), thrombocytopenia, diabetes mellitus, and B-cell lymphoproliferative disorders ${ }^{12}$. Thrombocytopenia is estimated to occur in $0.16 \%$ to $45.4 \%$ of people with chronic hepatitis $\mathrm{C}^{13}$. Putative associations with Hyde's prurigo nodularis ${ }^{14}$ and membrane proliferative glomerulonephritis. Hepatitis $\mathrm{C}$ infection is also associated with a condition called mixed cryoglobulinemia, which is inflammation of small and medium sized blood vessels (or vasculitis) caused by deposition of immune complexes involving cryoglobulins ${ }^{15}$.

\section{Materials and Methods}

The drug structure was constructed using hyperchem software, the energy, geometric optimization values are calculated. The pharmacore groups are identified and these are replaced in the original drug structure and the drug score, drug likeliness are calculated the top 5 screened models are taken into consideration.

All the steps were applied to these modified structures. These steps involve structural optimization, energy minimization, solvating and desolvating the ligand, finally the ligand preparation for docking and docking process. All the steps were done taking geometrically optimized structure and remaining steps are carried out. The structures was constructed in discovery studio software and some of the properties like ADME, toxicity was calculated. The hydrogen bond interactions were calculated using GOLD. The active site and hydrogen bond lengths were calculated.

\section{QSAR (Quantitative structure activity relationship)}

QSAR is a process by which chemical structure is quantitatively correlated with a well defined process, such as biological activity or chemical activity. 3D-QSAR refers to the application of force field calculations requiring 3D structures, based on protein crystallography. It uses computed potentials, the Lennar-Jones potential, rather than experimental constants and is concerned with the overall molecule rather than a single substituent. It examines the steric fields and the electrostatic fields based on the applied energy function.

\section{Molecule Mining}

It is a special case of structured data mining approached, apply a similarity matrix based prediction or an automatic fragmentation scheme into molecular sub structured by using graph kernels. Fragment based $\log \mathrm{P}$ of compound can be determined by the sum of its fragments. This method gives mixed results and is generally not trusted to have accuracy of more than $+/-0.1$ units.

\section{Hyperchem}

It is a sophisticated molecular modeling environment that is known for its quality, flexibility and ease of use. Uniting 3D visualization and animation with quantum chemical calculations, molecular mechanics and dynamics, HyperChem puts more molecular modeling tools at windows program. It includes all the components of structure, thermodynamics, spectra and kinetics.

\section{Geometry optimization}

It is used to find minima on the energy surface, with these minimum energy structures representing equilibrium structures. A geometry optimization is not much else than repeated single point calculations, where the positions of the atoms are updated according to the forces acting on them. It is used to find minima on the energy surface, with these minimum energy structures representing equilibrium structures. Optimization to minima is also referred as energy minimization. The energy of the molecules is reduced by adjusting atomic coordinates; It is applied to model-built structures as well as to those derived from co-ordinate data banks. It is done when using both molecular mechanics or quantum mechanics methods and it must precede any computational analyses in which these methods are applied.

\section{Molecular dynamics (MD)}

MD is one of the principal tools in the study of biological molecules. The computational method calculates the time dependent behavior of a molecular system. MD stimulations have provided detailed information on the fluctuations and conformational changes of proteins, nucleic acids and drug molecules. These methods used to investigate the structure, dynamics and thermodynamics of biological molecules and their complexes.

\section{Discovery Studio}

The tools Explorer provides access to tools that perform quickly on selected objects and are usually performed locally, as opposed to protocols, which are always sent to the server for processing. This makes them convenient for rapidly accessing functionality when working interactively with data in the visualization.

\section{Protocol Explorer}

It provides access to the available protocols. By default it is presented on the left side of the main application window. The steps are

Working with the protocols Explorer

To view the protocols explorer

To hide the protocols explorer 


\section{ADMET}

The ADMET descriptors protocol uses the QSAR models to estimate a ange of ADMET related properties for small molecules. The following properties and classes of properties can be computed

Aqueous solubility

Blood brain barrier penetration

Cytochrome P450 2D6 inhibition

Hepatotoxicity

Human intestinal absorption

Plasma protein binding

\section{Docking}

The molecular docking is to find the best protein-ligand complex geometry. It is usually large, different algorithms are used in order to accurately explore the space of possible conformations while decreasing the computational power needed for the docking calculation at the same time

\section{GOLD}

GOLD uses genetic algorithm to provide docking of exile ligand and a protein with exiles hydroxyl groups. The protein is considered to be rigid. This makes it a good choice when the building pocket contains amino acids that form hydrogen bonds with the ligand. Gold uses a scoring function that is based on favorable confirmation found on empirical results on weak chemical interactions. The development of GOLD is currently focused on improving the computational algorithm and adding a support for parallel processing. GOLD has one of the most comprehensive validation test and also available for use at CSC.

- The main steps in the methodology are

- Geometric optimization of molecule

- Changing the $\mathrm{R}$ - groups

- Solvating molecules

- Removing water molecule

- Protein optimization

- $\quad$ Protein and ligand preparation for docking

- Hydrogen bond interactions

PDB results

Swiss-PDB viewer is an application that provides a user friendly interface allowing analyzing several proteins at the same time. The proteins can be superimposed in order to deduce structural alignments and compare their active sites or any other relevant parts. Amino acid mutations, H-bonds, angles and distances between atoms are easy to obtain.

Table1: Identification of active site in the protein using PDB

\begin{tabular}{|c|c|c|}
\hline S.NO. & AMINO ACID NUMBER & ATOM NUMBER \\
\hline 1 & Val 37 & 263 \\
\hline 2 & His428 & 6281 \\
\hline 3 & Leu 492 & 7298 \\
\hline 4 & Ala 396 & 5754 \\
\hline 5 & Cys 223 & 3189 \\
\hline
\end{tabular}

Table 2: Listing of the fitness of the top-ranked individual for each ligand docked in GOLD

\begin{tabular}{|c|l|c|c|c|c|c|}
\hline S.NO & LIGANDS & FITNESS & S(HB_EXT) & S(VDW_EXT) & S(HB_INT) & S (VDW_INT) \\
\hline 1 & RIBAVIRIN & 31.54 & 6.00 & 21.16 & 0.00 & -3.55 \\
\hline 2 & R2=NH2 & 27.89 & 6.51 & 18.17 & 0.00 & -2.57 \\
\hline 3 & R1 \&R2=H & 28.47 & 0.00 & 21.35 & 0.00 & -1.14 \\
\hline 4 & R4=H* & 33.23 & 5.90 & 22.34 & 0.00 & -3.75 \\
\hline & R1=H R2=CH3 & & & & & \\
5 & R3=CH3 & $31 . .00$ & 1.13 & 21.54 & 0.00 & -1.09 \\
\hline 6 & R2,R3,R4=H & 31.48 & 2.00 & 21.98 & 0.00 & -0.74 \\
\hline
\end{tabular}

Table 3: Finding the fitness score of analogs

\begin{tabular}{|c|l|c|c|c|}
\hline S.No. & \multicolumn{1}{|c|}{ Ligand } & Y1(-) & Y2(-) & Y=Y1+Y2 \\
\hline 1 & RIBAVIRIN & -190.23 & -31.08 & -222.8 \\
\hline 2 & R2=NH2 & -192.65 & -27.89 & -221.87 \\
\hline 3 & R1 \&R2=H & -189.39 & -28.54 & -217.87 \\
\hline 4 & R4=H & -197.15 & -33.84 & -230.38 \\
\hline 5 & R1=H R2=CH3 R3=CH3 & -196.89 & -30.21 & -226.99 \\
\hline 6 & R2,R3,R4=H & -198.60 & -31.49 & -230.09 \\
\hline
\end{tabular}


A Study on the Biological activity of Hepatitis...

Table 4: Relative binding free energy

\begin{tabular}{|c|l|c|}
\hline S.No & \multicolumn{1}{|c|}{ Molecules } & Relative binding free energy \\
\hline 1 & $\mathrm{R} 2=\mathrm{NH} 2$ & 8.43 \\
\hline 2 & $\mathrm{R} 1 \& \mathrm{R} 2=\mathrm{H}$ & 5.09 \\
\hline 3 & $\mathrm{R} 4=\mathrm{H}$ & -7.99 \\
\hline 4 & $\mathrm{R} 1=\mathrm{H}$ R2=CH3 R3=CH3 & -1.19 \\
\hline 5 & $\mathrm{R} 2, \mathrm{R} 3, \mathrm{R} 4=\mathrm{H}$ & -6.43 \\
\hline
\end{tabular}

Table 5: ADME

\begin{tabular}{|c|c|c|c|c|c|c|}
\hline Ligand & BBB level & $\begin{array}{c}\text { Absorption } \\
\text { Level }\end{array}$ & $\begin{array}{c}\text { Solubility } \\
\text { level }\end{array}$ & $\begin{array}{c}\text { Hepatotoxicity } \\
\text { Level }\end{array}$ & CYP2D6 & PPB level \\
\hline Ribavirin & 4 & 3 & 5 & 1 & 0 \\
\hline 3R520=0NH2 & 4 & 3 & 5 & 0 & 0 \\
\hline R1 \&R2=H & 4 & 1 & 5 & 0 & 0 \\
\hline R4=H & 4 & 2 & 5 & 1 & 0 \\
\hline $\begin{array}{c}\text { R1=H R2=CH3 } \\
\text { R3=CH3 }\end{array}$ & 3 & 0 & 4 & 0 & 0 \\
\hline R2,R3,R4=H & 3 & 0 & 4 & 0 & 0 \\
\hline
\end{tabular}

Table 6: Molecular Properties

\begin{tabular}{|c|c|c|c|c|c|c|}
\hline Ligand & Mol-MW & Mol-Surface & Volume & Donor HB & Accept HB & $A \log P$ \\
\hline Ribavirin & 244.20 & 324.48 & 141.65 & 4 & 7 & -2.745 \\
\hline $\mathrm{R} 2=\mathrm{NH} 2$ & 215.17 & 283.93 & 124.16 & 3 & 6 & -2.23 \\
\hline $\mathrm{R} 1 \& \mathrm{R} 2=\mathrm{H}$ & 171.15 & 251.50 & 102.89 & 2 & 5 & -1.33 \\
\hline $\mathrm{R} 4=\mathrm{H}$ & 229.39 & 284.87 & 122.78 & 3 & 6 & -2.09 \\
\hline $\begin{array}{l}\mathrm{R} 1=\mathrm{H} \text { R2=CH3 } \\
\mathrm{R} 3=\mathrm{CH} 3\end{array}$ & 184.29 & 287.34 & 118.33 & 1 & 4 & 0.71 \\
\hline $\mathrm{R} 2, \mathrm{R} 3, \mathrm{R} 4=\mathrm{H}$ & 187.21 & 278.62 & 108.76 & 1 & 4 & 0.98 \\
\hline
\end{tabular}

Table 7: Toxicity

\begin{tabular}{|c|c|c|c|c|c|c|c|c|c|c|c|}
\hline \multirow[b]{2}{*}{ Ligand } & \multirow[b]{2}{*}{$\begin{array}{c}\text { Aerobic } \\
\text { biodegradabi } \\
\text { lity }\end{array}$} & \multirow[b]{2}{*}{$\begin{array}{c}\text { AMES } \\
\text { Mutagenici } \\
\text { ty }\end{array}$} & \multirow{2}{*}{$\begin{array}{c}\text { Developme } \\
\text { ntal } \\
\text { toxicity } \\
\text { potential }\end{array}$} & \multirow[b]{2}{*}{$\begin{array}{l}\text { Ocular } \\
\text { irritanc } \\
\quad \mathrm{y}\end{array}$} & \multirow[b]{2}{*}{$\begin{array}{l}\text { Skin } \\
\text { irritanc } \\
\mathrm{y}\end{array}$} & \multirow[b]{2}{*}{$\begin{array}{c}\text { Skin } \\
\text { Sensitiz } \\
\text { e }\end{array}$} & \multicolumn{5}{|c|}{ Carcinogenicity } \\
\hline & & & & & & & $\begin{array}{c}\text { Rode } \\
\text { nt }\end{array}$ & $\begin{array}{c}\text { Femal } \\
\mathrm{e} \\
\text { mouse }\end{array}$ & $\begin{array}{c}\text { Male } \\
\text { mous } \\
\mathrm{e}\end{array}$ & $\begin{array}{l}\text { Femal } \\
\text { e rat }\end{array}$ & $\begin{array}{c}\text { Male } \\
\text { rat }\end{array}$ \\
\hline Ribavirin & $\mathrm{NO}$ & $\mathrm{NO}$ & YES & $\mathrm{NO}$ & NO & $\mathrm{NO}$ & YES & $\mathrm{NO}$ & $\mathrm{NO}$ & YES & YES \\
\hline $\mathrm{R} 2=\mathrm{NH} 2$ & $\mathrm{NO}$ & $\mathrm{NO}$ & YES & $\mathrm{NO}$ & $\mathrm{NO}$ & YES & YES & $\mathrm{NO}$ & NO & YES & YES \\
\hline $\mathrm{R} 1 \& \mathrm{R} 2=\mathrm{H}$ & $\mathrm{NO}$ & $\mathrm{NO}$ & YES & $\mathrm{NO}$ & $\mathrm{NO}$ & $\mathrm{NO}$ & $\mathrm{NO}$ & $\mathrm{NO}$ & $\mathrm{NO}$ & YES & YES \\
\hline $\mathrm{R} 4=\mathrm{H}$ & $\mathrm{NO}$ & $\mathrm{NO}$ & YES & $\mathrm{NO}$ & $\mathrm{NO}$ & YES & YES & $\mathrm{NO}$ & $\mathrm{NO}$ & YES & YES \\
\hline $\begin{array}{l}\mathrm{R} 1=\mathrm{H} \\
\mathrm{R} 2=\mathrm{CH} 3 \\
\mathrm{R} 3=\mathrm{CH} 3\end{array}$ & YES & NO & YES & NO & $\mathrm{NO}$ & NO & NO & $\mathrm{NO}$ & NO & YES & YES \\
\hline $\mathrm{R} 2, \mathrm{R} 3, \mathrm{R} 4=\mathrm{H}$ & $\mathrm{NO}$ & $\mathrm{NO}$ & YES & $\mathrm{NO}$ & $\mathrm{NO}$ & YES & YES & $\mathrm{NO}$ & NO & YES & YES \\
\hline
\end{tabular}

Table 8: 2- D QSAR Properties

\begin{tabular}{|c|c|c|c|c|c|c|}
\hline Molecule & Ribavirin & $\mathrm{R} 2=\mathrm{NH} 2$ & $\begin{array}{c}R 1 \\
\& R 2=H\end{array}$ & $\mathbf{R 4}=\mathbf{H}$ & $\begin{array}{c}\text { R1=H R2=CH3 } \\
\text { R3=CH3 }\end{array}$ & $\mathbf{R 2 , R 3 , R 4 = H ~}$ \\
\hline Partial charges (e) & 0.00 & 0.00 & 0.00 & 0.00 & 0.00 & 0.00 \\
\hline Surface area [Appox] & 324.48 & 284.93 & 250.54 & 312.56 & 287.50 & 277.71 \\
\hline Surface area [Grid] & 421.89 & 378.42 & 328.65 & 405.53 & 352.66 & 367.77 \\
\hline Volume & 663.12 & 587.43 & 498.05 & 633.43 & 559.67 & 551.23 \\
\hline $\begin{array}{ll}\text { Hydration } & \text { Energy } \\
{[\mathrm{Kcal} / \mathrm{mol}]} & \\
\end{array}$ & -20.48 & -16.74 & -14.43 & -19.45 & -7.54 & -8.32 \\
\hline $\log \mathrm{P}$ & -2.05 & -1.68 & -0.95 & -1.45 & 0.48 & -0.64 \\
\hline Refractivity & 52.67 & 46.67 & 39.04 & 51.89 & 46.57 & 44.42 \\
\hline Polarizability & 21.11 & 18.65 & 39.09 & 20.47 & 18.50 & 17.36 \\
\hline Mass & 244.23 & 214.43 & 171.18 & 228.89 & 183.31 & 183.18 \\
\hline
\end{tabular}


Table 9: Finding of the Hydrogen bond interactions of analogs with Protein

\begin{tabular}{|l|c|c|}
\hline \multicolumn{1}{|c|}{ Ligand Molecule } & Amino Acid Name & Hydrogen Bond Distances $\mathbf{( A}^{\mathbf{0}} \mathbf{\text { ) }}$ \\
\hline Ribavirin & Arg 503 & 2.576 \\
& Leu 492 & 2.365 \\
\hline R2=NH2 & Arg 503 & 2.700 \\
\hline R1 \&R2=H & His 428 & 3.053 \\
& Ala 396 & 3.042 \\
\hline R4=H & Leu 392 & 2.789 \\
& & \\
R1=H R2=CH3 & Ala 396 & 2.804 \\
R3=CH3 & Arg 503 & 3.023 \\
\hline R2,R3,R4=H & & \\
\hline
\end{tabular}

\section{Results}

By rational based drug design approach, new analogs are designed by replacing pharmacophore groups in ligand. Docking is performed with the optimized analogs and protein binding free energy was calculated for each analogs. The analog with changed group $\mathrm{R} 4=\mathrm{H}$ is having lowest binding fee energy (-7.99) and will have the maximum binding affinity. In the AMDET prediction the modified ligand molecules are non-mutagenic and do not had any ocular and skin irritancy. From docking using GOLD ligand $\mathrm{R} 4=\mathrm{H}$ has more fitness (33.84) compared to the original drug fitness (31.08). The donor and acceptors of hydrogen are present in each ligand which shows the tendency of Hydrogen bonding for molecular interaction. From the QSAR studies of the analogs various physical, chemical and biological properties like polarizability, solubility, $\log \mathrm{P}$, refractivity, surface area and hydration energy.

\section{Conclusion}

A number of top molecules were screened for various guidelines including Gold score, H-bond energy and QSAR productivity results. For all these cases QSAR based screening only correlated with the experimental activity. From ADMET, toxicity, QSAR studies the analog $\mathrm{R} 4=\mathrm{H}$ is better than the original drug Ribavirin in fitness, toxicity level, mutagenic properties and does not have any side effects.

\section{REFERENCES}

[1.] Ryan KJ, Ray CG, (2004). Sherris Medical Microbiology (4th ed.). McGraw Hill. pp. 551-2.

[2.] Rosen, HR (2011)"Clinical practice. Chronic hepatitis C infection". The New England Journal of Medicine 364 (25): $2429-38$

[3.] Maheshwari, A; Ray S; Thuluvath PJ (2008) "Acute hepatitis C". Lancet 372 (9635): 321-32.

[4.] Bailey, Caitlin (2010). "Hepatic Failure: An Evidence-Based Approach In The Emergency Department".Emergency Medicine Practice 12 (4).

[5.] Houghton M (2009). "The long and winding road leading to the identification of the hepatitis C virus".Journal of Hepatology 51 (5): 939-48.

[6.] Nelson, PK; Mathers BM, Cowie B, Hagan H, Des Jarlais D, Horyniak D, Degenhardt L (2011) "Global epidemiology of hepatitis B and hepatitis C in people who inject drugs: results of systematic reviews". Lancet 378(9791): 571-83.

[7.] Chronic Hepatitis C Virus Advances in Treatment, Promise for the Future. Springer Verlag. (2011). pp. 103-104.

[8.] Halliday, J; Klenerman P, Barnes E (2011) "Vaccination for hepatitis C virus: closing in on an evasive target" (PDF). Expert review of vaccines $\mathbf{1 0}(5)$ : 659-72.

[9.] Mueller, S; Millonig G; Seitz HK (2009). "Alcoholic liver disease and hepatitis C: a frequently underestimated combination" (PDF). World journal of gastroenterology : WJG 15 (28): 3462-71

[10.] Alter, MJ (2011) "Epidemiology of hepatitis C virus infection" (PDF). World journal of gastroenterology : WJG 13 (17): $2436-$ 41.

[11.] Ozaras, R; Tahan, V (2009). "Acute hepatitis C: prevention and treatment". Expert review of anti-infective therapy 7 (3): $351-61$.

[12.] Zignego, AL; Ferri, C; Pileri, SA et al. (2007). "Extrahepatic manifestations of Hepatitis C Virus infection: a general overview and guidelines for a clinical approach". Digestive and Liver Disease 39 (1): 2-17.

[13.] Louie, KS; Micallef JM; Pimenta JM; Forssen UM (2011). "Prevalence of thrombocytopenia among patients with chronic hepatitis C: a systematic review". Journal of viral hepatitis 18 (1): 1-7

[14.] Lee, MR; Shumack, S (2005). "Prurigo nodularis: a review". The Australasian journal of dermatology 46 (4): 211-18; quiz 21920 .

[15.] Vannuzzella, F; Vaglio, A; Garini, G (2010). "Management of hepatitis C virus-related mixed cryoglobulinemia". Am. J. Med. 123 (5): 400-8. 